ISSN: 2162-3104 Print/ ISSN: 2166-3750 Online

Volume 8, Issue 2 (2018), pp. 1034-1058

(C) Journal of International Students

http://jistudents.org/

doi: $10.5281 /$ zenodo. 1250404

\title{
Survival Strategies of International Undergraduate Students at a Public Research Midwestern University in the United States: A Case Study
}

\author{
Linda Tsevi \\ University of Ghana, Legon
}

\begin{abstract}
In this qualitative study, I explored the strategies that international undergraduate students at a public research Midwestern university in the United States employ to persist and survive their educational transition to achieve academic excellence. Using Tinto's (1987) theory of persistence as the theoretical framework, this paper employed a case study method. Five undergraduate international students were interviewed via semi-structured in-depth interviews. The findings indicated that students experienced both academic and non-academic challenges. Strategies adopted included involvement in out-of-classroom activities and dependence on family and friends. Recommendations include requiring academic counsellors and university administrators to devise curriculum and programs to assist international students. Further, the teaching faculty should reach out to students who have English language challenges.
\end{abstract}

Keywords: challenges, persistence, international undergraduate students, strategies, survive

According to the Institute of International Education (IIE) Open Doors (2017) report, the population of international students increased from $1,043,839$ in $2015 / 2016$ to $1,078,822$ in $2016 / 2017$ academic school year indicating a three percent increase over the previous year. Several reasons have been assigned to the increasing growth of international students in the 
United States. Among the top reasons include 1) the U.S. is regarded as very welcoming to international students in comparison to other destinations of study, 2) the U.S. is noted as having an educational system that is of high quality, 3) the certificate/diploma obtained from U.S. assists in securing a job/employment in students' home country (IIE, 2016). The three leading countries where majority of international students emigrate from are China, India and South Korea. Students from these countries constitute $55.2 \%$ of the entire international student population that emigrated into the U.S. during the 2016/2017 academic school year (IIE, 2017). A working definition for an international student can be considered as an individual who is a citizen of another country but has enrolled in classes for credit at a recognized higher education institution in the United States of America.

International students financially boosted the U.S. economy with $\$ 39$ billion in 2016 as noted by the U.S. Department of Commerce (IIE, 2017). Major sources of funding for $73 \%$ of international students in the U.S. are from their home countries' governments and universities, family and personal sources. Funding from U.S. sources for international students constitute 27\% (Open Doors, 2015). Thus economically, international students have boosted the U.S. economy through the inflow of their external funding resources. They also bring diversity into the U.S. classroom by providing international perspectives in research such as in the physical sciences, social sciences and the humanities. These diverse perspectives develop American students for careers in the global world (Open Doors, 2015).

The growth in international students in the U.S. has translated into enrolment increases in various states. The top ten U.S. states that hosted international students for the 2016/2017 academic year were California, New York, Texas, Massachusetts, Illinois, Pennsylvania, Florida, Ohio, Michigan and Indiana. Each of the top ten states had on average an income of about $\$ 1$ billion from hosting international students. (IIE, 2017).

Upon their arrival to the U.S. international students learn to adjust and adapt to the new social, cultural and institutional environments. As they acclimatize to the changes, they also experience difficulties and challenges. In order to overcome them, they devise strategies that enable them persist in their respective colleges and universities and eventually graduate. The National Center of Education Statistics' 2016 report indicates that $60 \%$ of full-time undergraduate students who started a bachelor's degree at a fouryear institution in 2008 graduated within six years by 2014 (NCES, 2016). 
International students come from various countries across the world and also have varied educational backgrounds that differ from what pertains in the U.S. system. They have to adjust to the challenging academic environment and the American culture. The culture shock, classroom dynamics and student/professor relationship were different from what most international students were used to in their home countries (Swagler \& Ellis, 2003).

There have been a number of studies on international students regarding their persistence and resilience to succeed in U.S. higher education institutions, and how they are able to overcome their culture shock and adjust to classroom dynamics among others (Wang, Ahn, Kim \& Lin-Siegler, 2017; Wilton \& Constantine, 2003; Zhai, 2004;). However, few studies have focused on the persistence of varied groups of international students in U.S. colleges and universities (Andrade, 2006; Johnson, 2008; Miamisheishivili, 2012). Further, these studies did not focus specifically on persistence of international undergraduate students coming from the continents of Africa and Asia who happened to be in the same higher education institution.

The purpose of this qualitative study is to identify what enables international undergraduate students from Africa and Asia to persist through to their junior and senior years and not withdraw along the way. This study uses Tinto's (1987) theoretical framework, and the outcome will enable faculty members, university administrators and academic counsellors understand the experiences and challenges of undergraduate international students and devise curriculum and programs to assist them. To explore their experiences and challenges the researcher asked the following questions:

- How do international undergraduate students describe their college experience?

- How do they describe their challenges?

- What strategies do they adopt to survive the challenges in the U.S. educational system as related to academic achievement?

\section{LITERATURE REVIEW}

The increasing numbers of international students at various U.S. higher education institutions face challenges such as English language fluency, 
differences in instructional methods and the educational system in general (Olivas \& Li, 2006; Ota, 2013). In an effort to provide a bridge to the gaps in knowledge, the researcher will address previous studies done.

International students have stresses such as finance, housing, lack of social network and support, competence in the English Language and homesickness (Johnson, 2008; Behroozi-Bagherpour, 2010; Kitsos, 2012; Mamiseishvili, 2012; Wang et al., 2017). Andrade (2006) studied the firstyear experiences of seniors at a higher education institution in the U.S. The study noted challenges that international students have to address to include limited English proficiency, taking part in class discussions and building relationships with teachers. The answers to these challenges included establishing relationships with professors and friends, involvement in clubs, assistance from various university services, and socializing with students from diverse cultures. Similarly, Mamiseishvili (2012) studied factors affecting the persistence of first year college students. Positive factors included language proficiency, academic performance and academic integration.

Fass-Holmes (2016) measured the retention and graduation rates of international students at a West Coast public university. The author tested the hypothesis that struggling international students would have low retention and graduation rates. International students were noted as having struggled with such challenges as English writing, homesickness and loneliness. Six cohorts of international students were examined for this study. The outcome of the study did not confirm the hypothesis. Compulsory military service in their home country was the reason why some international students were unable to complete their program of study at this West Coast public university.

International students have to address the challenge of adjusting to different cultures and classroom requirements. Beykont and Daiute (2002) note that international students come from teacher-centered classrooms into an opposite educational environment where the focus is on the student.

The requirement for a supportive social network cannot be understated. International students have to garner the needed supportive social network in a foreign environment in order to be academically successful (Sawir, Marginson, Deumert, Nyland \& Ramia, 2008). Similarly, Mesidor and Sly (2016) indicate that students that have positive experiences on their first day in a foreign environment will be more welcoming to the adjustment process. 
Invariably, those who get the opportunity to experience support and friendship from host country's nationals adjust better in the foreign environment than those who do not (Ota, 2013). Further, a qualitative study by Swagler and Ellis (2003) of Taiwanese students attending university in the United States had dominant themes emerging as difficulty in establishing student-teacher relationship, problem with acquiring fluency in the English Language, and the significance of being independent.

The preceding literature review provides the framework indicating how international students adapt and deal with challenges. Subsequently, this study explores how international undergraduate students of Asian and African origin in a public research Midwestern university strategize and persist. In addition, this study explores best practices employed by these students at the same U.S. higher education institution.

\section{Theoretical Framework}

Tinto's (1987) theory of persistence is used as the theoretical framework for the study. According to Tinto (1987), there is the need for students to integrate socially and academically in order to foster persistence in college. The five components of this theory are pre-entry attributes, goals and commitments, institutional experiences, integration and outcome. Through the application of Tinto's theory, this study determines which components of the model are most applicable to international students in the strategies that they employ to persist in higher education institutions in the U.S.

The pre-entry attributes consist of prior schooling, family background, skills and abilities of the college student. This first component indicates that students attend college with various levels of pre-entry attributes. For instance, a student's gender, physical attributes, ethnicity and physical capabilities has a positive or negative impact on persistence in college. Further, social and intellectual skills, plus values that a college student has, impacts his/her ability to withdraw or persist in college.

The second component of this theory is goals and commitment. Tinto (1987) indicates that the intentions of the individual determine participation in college which culminates in achieving an occupational or educational goal. He notes that most students do not have their occupational goals as freshmen. However, a student who is able to determine a career path by the end of freshman year is more likely to persist in college. Also, being a member of an external organizations is an indication of external 
commitment that may negatively or positively impact a student's persistence. For students who have problems integrating socially, having a commitment to an external organization may make the difference between persistence and departure from college.

The third component is institutional experiences which are delineated into academic and social systems. Each of these have a formal and informal sub-component. The intellectual demands such as classroom lectures, course work and evaluations, that higher education institutions place on a college student constitutes part of the formal sub-component. The informal academic system includes the intellectual values of both students and members of the institution. These are exemplified by the meetings between faculty and students outside of the classroom environment to discuss intellectual issues. The social system includes structured activities that enable students to socialize with other students (Tinto, 1987). These extra-curricular activities consist of student governance, sports or other college-sponsored events. The informal social system consists of any interactional opportunities amongst students that are external to the college or university. These informal opportunities could take place both on and offcampus as the student desires.

\section{RESEARCH METHOD}

A public research university in the Midwest is the focus of this study. It has a current student population of 28,000 . The total number of international students is about 2,300 representing 110 countries and constitutes about $12 \%$ of the entire student population. Over 200 majors are offered including the physical sciences, engineering sciences, social sciences, business programs and the humanities.

The purpose of this case study is to determine how international undergraduate Asian and African students are able to persist from their freshman and sophomore years through to junior and degree completion years. Yin (2009) indicates that the case study enhances knowledge acquisition. It also enables the researcher to observe events directly and interview people having roles to play in the study (Yin, 2009). A case study is defined as "...an empirical inquiry that investigates a contemporary phenomenon within its real-life context, especially when the boundaries between the phenomenon and context are not clearly evident (Yin, 2003: 
13). Similarly, Stake (1995) also indicates that a case study examines indepth an event, program or activity within a certain time period.

According to Maxwell (2005), "informal data gathering" techniques such as "casual conversations" are required if that will help a researcher have access to the sample that is needed for the study. To establish a rapport with the participants, the researcher introduced herself as an international student who understood the challenges that are encountered in U.S. higher education institutions. Maxwell (2005) advocates that for a researcher to get the needed information from interviews there was the need to establish a harmonious relationship with the participants. The researcher employed observations and interviews in this case study.

\section{Participants}

This study was approved by the Institutional Review Board before participants were contacted. A total of five international undergraduate students were interviewed consisting of three males and two females. The participants agreed to participate in the study and signed consent forms. The identities of the participants were not revealed in the study to assure confidentiality and privacy. The questions that were posed to the interviewees included those that elicited perceptions and views from the participants without being led to a particular viewpoint. According to Rubin and Rubin (2005) the researcher must choose interviewees who are knowledgeable and experienced about the research problem. An interviewee having the required information about the research problem gives credibility to the research.

\section{Background Information on Participants}

The five participants represented four nationalities namely China, Ghana, Japan and Pakistan. Out of the five participants, three were seniors while two were juniors. Two of the participants were females and one of them was married. None of the male interviewees was married. The researcher used pseudonyms for the names of the participants because of ethical purposes.

\section{Chen}

Chen, a junior, is a female undergraduate student from China and she is the only married student in the sample. Her spouse is a post-doctoral student in Biology. She is majoring in Accounting and was enrolled at this institution during her sophomore year as a transfer student from China. 


\section{Amasan}

Amasan is a male undergraduate senior majoring in Economics. His home country is Ghana, and he began as a freshman at this university after completing High School in Ghana. He has been in the U.S. for the past four years. He looks up to his older brother who is a graduate student at this same institution.

\section{Rezan}

Rezan is a male undergraduate student from Pakistan. He came to the U.S. after completing High School in Pakistan, and is now a junior majoring in Business. He has travelled to a number of European countries before coming to the United States. Rezan is the older of two siblings and dotes a lot on his mother.

\section{JuXion}

JuXion is a female Journalism senior from Japan and she began as a freshman at this Midwestern university. She is the first of three siblings and has been in the U.S. for four years. She has an American boyfriend who assists her a lot with her academic work.

\section{Moustapha}

Moustapha is a senior from Pakistan and he transferred from another higher education institution in the U.S. during his sophomore year majoring in Engineering. He has lost both parents but his grandparents are alive and he is the youngest of three siblings. Moustapha transferred to this public Midwestern University because he liked the environment.

\section{Recruitment of Participants}

The five undergraduate student participants were purposefully selected (Merriam, 1998). Purposefully selecting an identifiable sample size enabled the researcher to identify cases that were rich sources of information (Merriam, 1998; Patton, 2002).

One main reason for this purposeful selection was because of the researcher's link to international student part-time workers at the institution's residential facility. The researcher had developed a collegial relationship with the student workers at this facility resulting in the ease at selecting the sample size of juniors and seniors for the study. This group of students were selected since they have survived their freshman and 
sophomore years and would therefore be in a better position to speak about the strategies they had developed that have enabled them to persist.

\section{Interviews}

The researcher interviewed the students at a time when they were not stressed out with academic, social or other related issues by allowing the participants to schedule their own interview times and venues. Some of the interview times were in the mornings and others were in the evenings. This helped them to be in a relaxed position to reflect on their years spent at this tertiary institution and speak freely without any inhibitions.

The researcher also cultivated the attitude of an "empathetic listener" as this relationship enabled the answering of research questions. However, Rubin and Rubin (2005) are of the view that a researcher should guard against being too empathetic. This is because this could limit an interviewer's questioning abilities by asking questions that put the interviewee in a "favorable" stance. Each interview lasted for an approximate time of 40 to 50 minutes for each participant and the questions asked were open-ended. The interviews were audio taped and they focused on impressions about classroom dynamics, classroom challenges, student services, social network, family and extracurricular activities.

Each recorded interview was transferred from the audio tape recorder onto a laptop computer and saved in a sound file and transcribed before the next interview was recorded. All the transcriptions were typed in Microsoft Word and participants who requested to review the transcribed interviews were given that opportunity. Member checking enabled triangulation of the data (Harvey, 2015). Thus participants were provided with copies of the transcribed interviews to ensure that whatever they said during the interview has been appropriately captured. This gave the participants the opportunity to agree with the transcripts or otherwise.

\section{Validity and Credibility}

Maxwell (2005) defines validity as "the correctness or credibility of a description, conclusion, explanation, interpretation, or other sort of account" (p. 106). To address validity issues in this study, a number of factors were examined. The researcher selected five undergraduate Asian and African junior and senior international students to obtain diverse opinions and information. Initially, to determine whether the open-ended questions would elicit the appropriate responses, the researcher did a pilot- 
test of the interview questions on an international student. Thus, required changes were made to the interview protocol based on this pilot study. To ensure that participants informed the researcher accurately about their experiences, they were assured anonymity in the study. Also, the researcher interviewed them at quiet locations where the students were relaxed and talked about their challenges and experiences without holding back. These participants have survived their freshman and sophomore years, and would therefore be in a better position to speak about the strategies they had developed which have assisted them to persist.

\section{Data Analysis}

Qualitative data analysis, is noted by Miles and Huberman (1994) as being made up of "data reduction, data display, and conclusion drawing/verification...." (p. 10), happening at the same time. Creswell (2009) indicates that data analysis "involves making sense out of text...." (p. 183). The first phase of interview analysis included transcription of interviews, memos, coding data into substantive and theoretical categories and summaries (Rubin and Rubin 2005; Maxwell 2005). The researcher critically read through all the interview transcripts several times and noted quotes, sentences and statements that emerged. The researcher also looked for linkages and patterns between themes.

After the transcription of the interviews, a thematic a priori coding generated from the literature review and Tinto's (1987) theory enabled the coding process. According to Creswell (2009) a priori codes are generated from existing literature before the data is examined. Coding was done manually by reading through the interview transcripts several times to look for repeating ideas, statements, quotes and sentences that were relevant to the research questions. This also enabled the researcher to accurately determine which thematic coding category to apply to words selected from the transcripts. The codes were applied to sentences/statements in the interview transcripts and themes were generated from repeating ideas (Auerbach \& Silverstein, 2003). Some sentences/statements did not have any of the thematic codes applicable to them, and others had more than one applicable code. The researcher used coding categories such as "academics' and provided sub-codings such as 'teacher-centered, student-centered,' 'specific acts,' and 'strategies;' "social network" had sub-codings as 'extracurricular activities,' 'influence of American friends and families, 'involvement in clubs and organizations.' Other codes were "conditions that 
made them persist" and "usage of student services." Ultimately, codes were used to generate categories and themes by aggregating similar codes together. A second coder reviewed data and identified major categories and themes based on the research questions posed for this study. This helped to determine the accuracy of the identified categories and themes. Further, a peer reviewer read through all the data and coded segments into categories and themes.

\section{Observation}

The researcher's initial interest in this topic was because as a former international student there have been lived experiences of persistence. The researcher was interested in knowing whether there were any shared commonalities as experience had shown that international students have to work hard in order to graduate within the required timeframe. One major challenge that the researcher had to overcome was adapting to the American academic writing style. Social interaction was also very important because it was through socialization that friends were made, and they came in handy when clarifications were needed about issues like class projects.

The first culture shock the researcher encountered was the differences in higher education environments. For example, the researcher had wrongly assumed that all higher education institutions in the U.S. were situated in highly populated towns and had good public transportation network. The researcher found that some colleges and universities were situated in quiet, less populous towns with varied transportation systems. Further, the researcher relied greatly on international and American students for relevant information by constantly interacting with them. These experiences made the researcher appreciate the interviewees' responses and be sensitive to whatever information they offered. On the other hand, these experiences could also cloud the researcher's judgment if caution was not taken about the peculiar circumstances. Further, the researcher may unconsciously look out for certain information if the responses do not align with what was expected. Ultimately, these experiences made the researcher passionate about the topic of study.

\section{RESULTS}

The themes that emerged from the data included: differences in home countries' educational experience, overwhelmed by academic work, 
challenges and strategies used. The findings from the study are organized in accordance to the research questions of the study.

\section{Differences in Home Countries' Educational Experience}

A majority of the participants articulated that the educational experiences in their home countries were different from what they have in the United States. Their home countries educational environment was more teacher-centered than student-centered as perceived in the United States. It must be noted that participants who came from China and Japan had a lot of difficulty with English language acquisition and speaking (Ota, 2013), while those who came from countries that were colonized by the British (Ghana and Pakistan) were quick to learn the different terminologies of American English. Thus among the participants, there were differences in the educational experiences between those countries colonized by the British and those that were not.

\section{Overwhelmed by Academic Work}

One of the themes that came up was specific acts in the classroom environment that the participants were exposed to. A majority of the participants noted that they were overwhelmed by the academic work initially. Amasan (from Ghana) said:

I was overwhelmed because I thought it was going to be what I was used to in Ghana. The educational system was different and I thought it was something like you study long hours but it was absolutely different. It was like you had to be smart in your studies because you couldn't really study or read everything. And you have to create a friendly environment for yourself where you feel comfortable.

The participant further noted that the classroom setting was more of a discussion which was very different from what he was accustomed to. This view of Amasan was reechoed by the JuXion (from Japan) who noted:

...because I am not a native speaker, it took me more time to write a paper and also I think one of the biggest challenge is some of my classes had discussion sessions and since I was not really fluent in English, I didn't know what to say in class and sometimes I did not get a good grade because my class participation was not enough. 
Chen (from China) also affirmed this view by noting that "for the Chinese student you have to take more time to read and know the requirements for a project than the American student. So as an international student I have to work very hard." These preceding statements confirm Kuo's (2011) study that international students have problems acquiring fluency in the English Language.

The language challenge had a profound impact on three of the participants interviewed. However two of the participants (Rezan and Moustapha) who were from Pakistan were not very perturbed by the classroom dynamics. They were quite conversant with some aspects of the classroom requirements since they had attended U.S. modeled High Schools in their home country. Thus, they were conversant with some of the classroom requirements during their freshman years. It was when they started their upper level courses in their sophomore, junior and senior years that they found the courses challenging. Rezan (from Pakistan) noted that “... as a freshman, you do not take very difficult classes. The electives I took were easy, but after getting into my sophomore year, the classes I took were quite tough and challenging."

All the participants were not used to the classroom situation where students could sometimes challenge what the professor was saying. There was the realization on the part of the participants that students were much more outspoken in class and were not afraid to make their views known, something that the international students lacked. Wan (2001) indicates that in U.S. higher education institutions, it is appropriate for a student to interrupt a professor who is lecturing in class. This differed from what pertained in the educational system of the participants' home countries. According to Beykont and Daiute (2002), international students come from a classroom that is teacher-centered into an opposite educational environment that is student-centered.

The liberty of the American students in class was something that was strange to all the participants such as eating and talking back to the professor in class. Moustapha (from Pakistan) noted:

...in my home country you cannot eat, chew gum or put your feet on the table in class. It was considered as very disrespectful to the instructor. But in terms of academic requirements it was the same in the home country as it was in the United States. 


\section{Challenges}

All the participants had one form of challenge or the other that they had to deal with and overcome. The emerging themes included the challenge with fluent English language acquisition/readings for class, living independently and making optimum use of student services.

\section{English Language Acquisition/Readings for Class}

The first challenge for Chen and JuXion, participants from China and Japan respectively, was fluent English language acquisition, thus they had to take intensive classes at the Applied English Center. Chen noted:

The teaching style is different, but first of all the language is different. I had to learn the language by taking classes at the Applied English Center. The writing style is also different, so I had to learn how to write in an academic institution.

However, Rezan and Moustapha rather felt the learning of English language terminologies was easier in the U.S. higher education system than what pertained in their home country, Pakistan. Moustapha noted:

I think it is much easier over here in the USA than in my home country. The reason being that, English is my second language and it was the medium of communication back home as well. So English was not a problem in terms of understanding what was going on in the classroom.

Another academic challenge was the skill required to do all class readings. Amasan (from Ghana) stated:

Yes, I did encounter some academic challenges, especially when it comes to readings for each class, I had a challenge there. I am the kind of person that will do all the readings like word for word and I realized that it will not be possible to read everything word for word. What you have to do is that you have to be smart about how and what you read. The Americans in the class will just skim through and I will take my time and read word for word and try to relate things by indicating why this thing is like this or that. I wasn't learning anything in the sense that I will only finish half the book and I will go to class and not be ready to participate as much as I will want. 
The above statement acknowledges the importance of being acquainted with the classroom dynamics of an American higher education institution. This is because without knowing the classroom dynamics, a student will have difficulty participating successfully in class. Olivas \&Li (2006) affirmed the distinguishing characteristics of the American educational system when compared to other educational systems. Participants explained that required class readings for example needed some level of skimming through to determine the important parts of the reading if one has to adequately prepare for a class.

\section{Living Independently and Homesickness}

The ability to live an independent life was a challenge for some of the participants who had lived with their families in their home country until their trip to the United States as college students. For instance, some of the students were not used to paying bills and doing laundry. One of the participants (Moustapha) noted:

Some of the challenges that I encountered were paying my bills on time and doing my own laundry. In my home country, somebody does that for me so it was a real challenge when I had to do these things on my own. These were some of the things that I found initially difficult and challenging as I had not been on my own before. But now I have kind of overcome that, even though I still have to struggle with that sometimes. I live in a fraternity and sometimes I am not able to pay my bills on time.

The preceding statement indicates the non-academic struggle of an international undergraduate student. As an adult, this participant was finding it difficult living an independent life and taking certain responsibilities serious such as paying bills on time. However, that did not affect his persistence (Fass-Holmes, 2016; Swagler \& Ellis, 2003).

Further, some of the participants had to struggle with being accepted by American students, as well as dealing with isolation and homesickness. Rezan (from Pakistan) notes that "being acceptable to American people was also a challenge, and staying away from family was very difficult. Homesickness and adjusting to the food, was not easy" (Sawir et al., 2008).

\section{Optimum Patronage of Student Services}

Participants had a challenge of making optimum use of some Student Services offered on campus. Three (Rezan, Moustapha and Chen) 
out of the five participants noted that they have never used the services of the University's Writing Center, even though all of them acknowledged having used both the Recreation Services Center and the Career Services. Two participants (Amasan and JuXion) who had used the Writing Center were not satisfied with the services they had received. They therefore resorted to using American friends and class colleagues to read over their papers. JuXion who is in her senior year noted:

I have been to the Writing lab but was not satisfied with the service. I will rather give my work to my American boyfriend to examine for me. I have however used the Career Services a number of times and also the Recreation Center three or four times during my four-year stay.

The minimal patronage of the Writing Center by students was reiterated by Amasan. He used strong words in his critique of the Writing Center by noting:

I have used the writing lab ... and there was another student just like me and the person had no idea of what I was talking about and I think that it is quite disappointing. Even though they say it is a writing lab they are just hiring ordinary students who know absolutely nothing. They think they are native speakers but it is just on my level. For example, they will tell you that you 'put a punctuation here' and I am like I am not here because of the punctuation, I am worried about the content - how do you understand it and how do you explain it as a reader to yourself? I don't think they know as much as they think they do because they are just ordinary students who are there working for money.

The preceding quote indicates that some participants were dissatisfied with some services offered at the Writing Center at this Midwestern University. Invariably, the use of one's social network is noted as beneficial in this instance. JuXion indicated that she relied on her American boyfriend to review her writing (Ota, 2013; Sawir et al., 2008; Wang et al., 2017). 


\section{Strategies Used}

The participants used various strategies to persist and overcome their varied challenges. They proffered varied reasons as to what enabled them to persist. However, the dominant themes were the extensive use of their social network such as friends, family and involvement in out-ofclassroom activities.

\section{Influence of Friends}

The research findings indicate that female participants had support from either their spouses or boyfriends in addition to other American friends. Chen indicated the help she had from her American girlfriend and spouse as follows:

My husband is a post-doc student. His major is Biology so when I took classes in Biology and Chemistry, he helped me out a lot. At my work place there is one American girl who is a part-time student who also helps me out a lot. Sometimes I can ask her questions about the American History class and she helps me out.

JuXion also agreed that friends plus having a positive relationship with professors were very important. She noted:

I think friends are very important factors. For example, American friends helped me understand the language. And also by talking to other people who have had similar experiences...they sometimes suggest to me to take this course or that elective? And also personal connection to professor also helps a lot. For example, when I talk to professors in person, they also encourage me that you can always come and ask questions.

The preceding indicates the value of friendship and the importance of developing a relationship with professors as noted by Andrade (2006).

The male participants did not indicate about obtaining support from girlfriends. They only noted that they had a number of American friends and it was one of the factors that enabled them to persist. Amasan noted:

I think what helped me to stay on is finding people who associate with you. Definitely, there are going to be pitfalls along the way. I think it basically has to do with your freshman 
and sophomore years...the kind of friendships that you are able to make. I also think it depends on you the individual and your objective of coming to school in the U.S. If you are coming here to just party, then that person may most probably not be successful in school....So you tell yourself I am here for this reason and I have met this group of people. They have fun but also know their priorities.

The preceding interview excerpt indicates that participants made extensive use of their social network and experienced the support and friendships cultivated from nationals of the host country. International students who had these supporting friendships in their freshman and sophomore years were able to adjust better in the foreign environment than those who did not (Hechanova-Alampay, Beer, Christiansen \& Van Horn, 2002; Ota, 2013; Sawir et al., 2008). According to Tinto (1987) when a student is socially involved with peers and has valuable educational experiences, it enables persistence.

\section{Family Connections}

Another overarching theme was the role of the family which emerged as a great influential factor which enabled them to persist. JuXion noted: "Yes my family has been very supportive financially because I did not come here with any scholarship." Rezan says his father puts a lot of pressure on him to perform. He noted: "My Dad works with UNICEF so he puts a lot of pressure on me to perform. He has colleagues whose sons are performing in universities in the United States so there are these pressures to do well."

Amasan also spoke about the influence of his brother and his brother's friends:

When I first came here, I did not know anyone apart from my brother who was also a student here, so I started hanging out with my brother's friends. Some of my brother's friends were juniors and seniors in various prestigious programs so it motivated me to set higher standards for myself....So that kind of social network really helped me.

These excerpts were consistent with research that affirm that international students will contact family and friends first when they have any issues because of shared commonalities such as same culture and 
language (Zhai, 2004). Further Tinto's (1987) theory has indicated that the individual's social skills, status of family and community, influence whether a student persisted or departed from college. Thus the preceding quote indicating motivation of family and friends, confirmed Tinto's (1987) theoretical component emphasizing pre-entry attributes.

\section{Involvement in Out-Of-Classroom Activities}

Another factor that enabled the participants to persist was their involvment in out-of- classroom activities. Some were presidents of student organizations, volunteered for institutions or even worked part-time oncampus. Amasan was the former president of the African Students Association, and Rezan noted that his part-time work on-campus enabled him to improve his communication skills because he was able to interact with a lot of people. Moustapha was the president of the Pakistan Students' Association. JuXion volunteered for a number of activities which helped her major in Journalism. She noted:

I used to read news on the campus radio ..., and also I use to go to the yoga club, and I sometimes help my friends sponsor the Japanese festival. Sometimes I also write an opinion column for the newspaper....These extracurricular activities have helped me to make more friends and understand more about the culture of the American people. It has definitely helped my career as Journalism major.

The preceding quote has indicated the influence of out-of-classroom activities in the persistence of international students at U.S. tertiary institutions further affirming Tinto's theory. Tinto $(1987,1998)$ noted that a student who was socially and academically integrated in the university community, persisted. However, Tinto (1998) added that a student could persist in college when he/she was either socially or academically integrated or has both values.

It must be noted from this study that the location of a higher education institution also enabled persistence. For instance, Moustapha, who transferred from a university in the Northeast, said he had continued to stay at this Midwestern university because of the safe and quiet environment, low cost of living and libraries that do not close during finals exams' week. In addition to these strategies, the participants had to work hard on their academics. For instance, Amasan had to find a way of getting all his 
readings done before the beginning of class in order to be abreast with what the class was studying.

\section{DISCUSSION AND CONCLUSIONS}

This study explored the various strategies that international students employed in order to persist and foster resilience at a public research Midwestern university within the framework of Tinto's (1987) persistence theory. The outcome of the study noted themes including differences in home countries' educational experience, being overwhelmed by academic work, challenges and strategies used by international undergraduate students that enabled them to persist in college.

Findings from the study showed that participants perceived their educational experience in the U.S. differently from what pertained in their respective home countries. They were surprised at the liberty of American students in the classroom since they were coming from a teacher-centered class, and thus found the student-centered class surprising. Findings agree with several studies that indicate that international students come from a classroom that is teacher-centered into an opposite educational environment that is student-centered (Beykont \& Daiute, 2002; Wan, 2001). Results also show that majority of the participants were overwhelmed by the academic work initially, thus they needed to work extra hard to be abreast with the class since English was their second language. Participants also had to devise methods to ensure that the required readings were done before the start of class to enable understanding of what the professor had to teach. This was an unexpected finding.

The study further indicated that participants employed varied ways to enable them to persist. Family, as well as American and international friends played critical roles in the persistence of international students. The female participants had support from their partners, whereas the male participants emphasized friends in addition to close relations (Mesidor \& Sly, 2016; Ota, 2013; Sawir et al., 2008)

Further, participants' involvement in extra-curricular activities led to a sense of belongingness in the community that took away loneliness. It was evident that the social network of the participants coupled with family support and hard work played very essential roles in their persistence and ultimate degree completion (Mesidor \& Sly, 2016). These findings support Tinto's (1987) theory that when students were socially integrated and 
involved in extra-curricular programs of the institution, there was a positive likelihood that they would persist in college. Research indicated that the absence of a social network, support and homesickness negatively affected an international student's persistence (Andrade, 2006; Johnson, 2008; Mamiseishvili, 2012).

The importance of student involvement in out-of-classroom activities such as in student-run organizations was also highlighted as very significant if they were to persist in universities. International students should be encouraged and motivated to get involved in out-of-classroom activities in addition working diligently on their academic pursuits (Axelson \& Flick, 2011; Kuh, Cruce, Shoup, Kinzie, \& Gonyea 2008).

Findings from the study indicate challenges that participants had to address during their freshman and sophomore years to include English language acquisition, living independently, making optimum use of student services, acceptability and homesickness (Swagler \& Ellis, 2003; Ota, 2013). Gaining fluency in the English language in U.S. higher education institutions has been an issue for international students especially those coming from countries that did not have English as the official language. Participants that had English as the official language in their home countries also had difficulty catching up with required reading assignments. Kuo (2011) found that participants had problems understanding what the professor was saying partly because of differences in accent and the speed at which the English language was spoken. The study recommended that the teaching faculty members should make the extra effort at reaching out to international students who have English language issues.

\section{Limitations of Study}

The data of this study would have been richer if partners and family members of the participants representing four nationalities had been interviewed. Given the fact that the participants came from differing socioeconomic backgrounds, this study could have explored that factor to determine how it impacted persistence. Also, this study did not interview faculty members, administrators and staff of International Student and Scholar Services about their knowledge of strategies that international undergraduate students utilize to persist in college. A quantitative study on the persistence of international students would also be of relevance to higher education institutions and the academia. 


\section{IMPLICATIONS}

This study has revealed compelling reasons indicating why international undergraduate juniors and seniors are able to persist in a U.S. higher education institution by using Tinto's (1987) theory as a basis for the study. Findings from this study suggest that though most of the participants were challenged academically and socially initially, they overcame these challenges through hard work and dependence on the support of partners, family and their various social networks. In addition to their being integrated socially and academically on campus, findings indicate that participants were very much involved in extra-curricular activities both oncampus and off campus. These activities further enabled their persistence. The researcher believes that these findings have significant implications for university administrators and staff of the International Student and Scholar Services in their programming activities for international students. Knowing the strategies that these participants used to survive would also be of great benefit to administrators of higher education institutions. It is suggested that institutions hosting international undergraduate students should continue to develop programs that will aid their social and academic development and thus promote their persistence as the population of international students continues to increase.

\section{REFERENCES}

Andrade, M. S. (2006). International student persistence: Integration or cultural integrity? Journal of College Student Retention 8 (1), 57-81.

Axelson, R. D. \& Flick, A. (2011, January/February). Defining student engagement. Change, 38-43. Retrieved from www.changemag.org

Auerbach, C. F. \& Silverstein, L. B. (2003). Qualitative Data. New York and London. New York University Press.

Beykont, Z. F., \& Daiute, C. (2002). Inclusiveness in higher education courses: International student perspectives. Equity \& Excellence in Education 35(1), $35-42$.

Behroozi-Bagherpour, P. (2010). International student retention in a large Texas urban community college." $\mathrm{PhD}$ dissertation, Sam Houston State University. ProQuest (ATT 3448042)

Constantine, M. G., Anderson, G. M, Berkel, L. A., Caldwell, L. D. \& Utsey, S. O. (2005). Examining the cultural adjustment experiences of African international college students. Journal of Counseling Psychology, 52(1), $57-66$. 
Creswell, J. W. 2009. Research design: Qualitative, Quantitative, and Mixed Methods Approaches. Third Edition, Thousand Oakes, CA: Sage Publications Inc

Fass-Holmes, B. (2016). International undergraduates' retention, graduation, and time to degree. Journal of International Students, 6(4), 933-955.

Harvey, L. (2015). Beyond member-checking: A dialogic approach to the research interview. International Journal of Research \& Method in Education, 38, 23-38.

Hechanova-Alampay, R., Beehr, T. A. Christiansen, N. D., \& Van Horn, R.K. (2002). Adjustment and strain among domestic and international student sojourners: A longitudinal study. School Psychology International, 23 (4), 458-474.

Johnson, V. L. (2008). "Barriers to enrollment, admissions, and retention for international students in the U.S. postsecondary education system." $\mathrm{PhD}$ dissertation, Capella University, ProQuest (ATT 3329830).

Institute of International Education. (2016). New IIE paper reveals what international students think about U.S. higher education. Institute of International Education, Inc.

Institute of International Education. (2017). New international student enrollment, 2006/07-2016/17. Open Doors Report on International Educational Exchange. Retrieved from http://www.iie.org/opendoors

Kitsos, J. (2012). Academic Persistence of International Student-Athletes at NCAA Division I Institutions.” PhD dissertation, New York University, 2012, ProQuest (ATT 3511425).

Kuh, G. D., Cruce, T. M., Shoup, R. Kinzie, J. \& Gonyea, R. B. (2008). Unmasking the effects of student engagement on first-year college grades and persistence. The Journal of Higher Education, 79(5).

Kuo, Y. (2011). Language challenges faced by international graduate students in the United States. Journal of International Students, 1(2), 38-42.

Mamiseishvili, K. (2012). International student persistence in U.S. postsecondary institutions. Higher Education: The International Journal of Higher Education and Educational Planning, 64(1), 1-17.

Maxwell, J. (2005). Qualitative research design, $2^{\text {nd }}$ ed. Thousand Oaks, CA: Sage Publications.

Merriam, S. 1998. Qualitative research and case study applications in education. San Francisco, CA: Jossey-Bass.

Mesidor, J. K., \& Sly, K. F. (2016). Factors that contribute to the adjustment of international students. Journal of International Students, 6(1), 262-282.

Miles, M. B. \& Huberman, M. (1994). Qualitative data analysis: An expanded source book. Second Edition. SAGE Publications. 
National Center of Education Statistics. (2016). The Condition of Education 2016 (NCES 2016-144), Undergraduate Retention and Graduation Rates. https://nces.ed.gov/fastfacts/display.asp?id $=40$

Olivas, M., \& Li, C. (2006). Understanding the stressors of international students in higher education: What college counselors and personnel need to know? Journal of Instructional Psychology, 33(3), 217-222.

Ota, A. (2013). Factors influencing social, cultural and academic transitions of Chinese international ESL students in U. S. higher education. (Doctoral dissertation). Portland State University.

Open Doors, (2015). Press Release - International Education Exchange: International Students in the U.S. Up by Ten Percent to Nearly One Million; Study Abroad by American Students Picks Up; Retrieved May 9, 2016 from http://www.iie.org/Who-We-Are/News-and-Events/PressCenter/Press-Releases/2015/2015-11-16-Open-Doors-Data

Patton, M. Q. (2002). Qualitative research and evaluation methods. $3^{\text {rd }}$ ed. Thousand Oaks, CA: Sage Publications.

Rubin, H. \& Rubin, I. (2005) Qualitative interviewing, $2^{\text {nd }}$ ed. Thousand Oaks, CA: Sage Publications.

Sawir, E., Marginson, S., Deumert, A., Nyland, C. \& Ramia, G. (2008). Loneliness and international students: An Australian study. Journal of Studies in International Education, 12(2), 148-180.

Swagler, M. A., \& Ellis, M. V. (2003). Crossing the distance: Adjustment of Taiwanese graduate students in the United States. Journal of Counseling Psychology, 50(4), 420-437.

Tinto, V. (1987). Leaving college: Rethinking the causes and cures of student attrition. Chicago: The University of Chicago Press.

Tinto, V. (1998). Colleges as communities: Taking research on student persistence seriously. The Review of Higher Education, 21, 167-177.

Wan, G. (2001). The learning experience of Chinese students in American universities: A cross-cultural perspective. College Student Journal, 35(1), 28-44.

Wang, I., Ahn, J. N., Kim, H. J., \& Lin-Siegler, X. (2017). Why do international students avoid communicating with Americans? Journal of International Students, 7(3), 555-582.

Wilton, L., \& Constantine, M. G. (2003). Length of residence, cultural adjustment difficulties and psychological distress symptoms in Asian and Latin American international college students. Journal of College Counselling, 6(2), 177-186.

Yin, R. K. 2003. Case study research: Design and methods. Third edition. Thousand Oaks, CA: Sage.

Yin, R. K. 2009. Case study research: Design and methods. Fourth edition. Thousand Oaks, CA: Sage. 
Zhai, L. (2004). Studying international students: Adjustments issues and social support. Journal of International Agricultural and Extension Education, 11(1), 97-104.

LINDA TSEVI graduated with a PhD from the Department of Educational Administration and Policy Studies, State University of New York at Albany in 2015. Currently, Linda Tsevi is a Lecturer at the University of Ghana Learning Centers, School of Continuing and Distance Education, College of Education. Correspondence concerning this article should be addressed to Linda Tsevi, PhD, University of Ghana Learning Centers, School of Continuing and Distance Education, College of Education, P. O. Box LG 1181, Accra, Ghana. Email: ltsevi@ug.edu.gh

Manuscript submitted: April 17, 2017

Manuscript Revised: May 25, 2017 Accepted for publication: August 14, 2017 